See Article page 92.

\section{Commentary: Under pressure: Managing superior vena cava syndrome after right ventricular assist device cannulation}

\author{
Jennie H. Kwon, MD, ${ }^{a}$ and Arman Kilic, $\mathrm{MD}^{\mathrm{b}}$
}

Percutaneous ventricular assist devices continue to gain popularity as temporary mechanical circulatory support for left ventricular, right ventricular, and biventricular failure. In particular, the percutaneously inserted dual-lumen Protek Duo cannula is an increasingly attractive option to support right ventricular failure, a relevant surgical problem in an era of increasing use of left ventricular assist device implantation and heart transplantation. The device is inserted via the internal jugular vein, avoiding femoral or open surgical cannulation, and allows for patient extubation and ambulation. As experience with these devices continues to accumulate, reports of complications and novel management strategies are expected.

In their case series, Badu and colleagues ${ }^{1}$ report a previously undescribed complication of iatrogenic superior vena cava (SVC) syndrome after percutaneous right ventricular assist device (RVAD) cannulation in the right internal jugular vein. The authors describe 2 patients who developed facial edema, plethora, and venous distension in the neck within 24 hours following cannulation. This was an uncommon complication in their series, occurring in only 3 patients out of 40 who underwent Protek Duo cannulation at their institution. In addition, they report their novel intervention in which a left subclavian venous cannula is added to the RVAD circuit to decompress the brachiocephalic system, which led to rapid resolution of symptoms.

\footnotetext{
From the ${ }^{\mathrm{a} D i v i s i o n}$ of Cardiothoracic Surgery, Medical University of South Carolina, Charleston, SC; and ${ }^{b}$ Division of Cardiac Surgery, The University of Pittsburgh Medical Center, Pittsburgh, Pa.

Disclosures: Dr Kilic serves on an advisory board for Medtronic. Dr Kwon reported no conflicts of interest.

The Journal policy requires editors and reviewers to disclose conflicts of interest and to decline handling or reviewing manuscripts for which they may have a conflict of interest. The editors and reviewers of this article have no conflicts of interest.

Received for publication Dec 2, 2020; revisions received Dec 2, 2020; accepted for publication Dec 15, 2020; available ahead of print Dec 25, 2020.

Address for reprints: Arman Kilic, MD, University of Pittsburgh Medical Center, 200 Lothrop St, Suite C-700, Pittsburgh, PA 15213 (E-mail: kilica2@upmc.edu).

JTCVS Techniques 2021;6:97-8

2666-2507

Copyright (C) 2020 The Authors. Published by Elsevier Inc. on behalf of The American Association for Thoracic Surgery. This is an open access article under the CC BY-NCND license (http://creativecommons.org/licenses/by-nc-nd/4.0/).

https://doi.org/10.1016/j.xjtc.2020.12.020
}

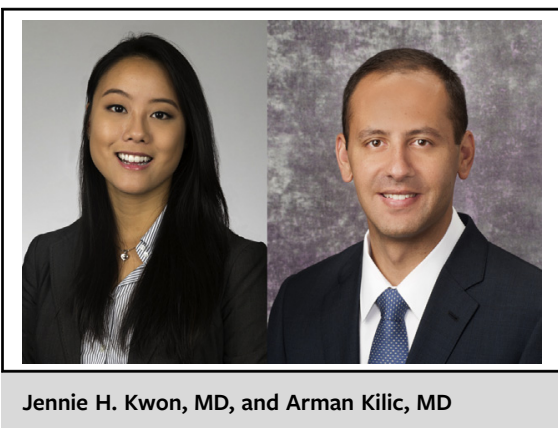

CENTRAL MESSAGE

Percutaneously inserted right ventricular assist devices offer a novel nondebilitating mechanism for right ventricular support, but complications are not yet completely described.

The incidence of this complication outside this report is unknown. There is little published experience with the Protek Duo, and only 2 retrospective case series describe patients cannulated with the Protek Duo for right ventricular support, evaluating a total of 44 patients. ${ }^{2,3}$ Although tricuspid regurgitation ( $36 \%$ ), anticoagulation-related hemorrhage $(29 \%)$, hemolysis $(17 \%)$, and device migration $(7 \%)$ are relatively common, SVC syndrome has not been described previously. However, this new report of the complication of SVC syndrome reveals little about the physiological mechanism for venous congestion. The authors speculate that anatomic characteristics may have predisposed these patients to SVC syndrome, as all 3 patients who developed this complication had smaller SVC length and diameter compared with the general cohort. Notably, the Protek Duo cannulas are large, available in 29 and 31 Fr. Other potential mechanisms for SVC syndrome include thrombotic occlusion of the central veins or the cannula or suction occlusion of the inflow channels against the right atrium or SVC. However, this complication occurred in these patients without evidence of thrombotic occlusion or cannula malposition. Furthermore, only 1 of 3 patients had higher RVAD peak flow and speed compared with the general cohort.

It is important to fully understand the complications associated with percutaneous RVAD. Protek Duo cannulation is increasingly popular not only in cardiac surgery settings, but also in providing venovenous extracorporeal membrane oxygenation for hypoxic respiratory failure. Acute SVC 
syndrome, as would be encountered with Protek Duo cannulation, does not allow for venous collateralization as seen in more chronic etiologies and is potentially life-threatening owing to cerebral edema or central airway obstruction. This new report alerts our community to be vigilant in detecting this potentially morbid condition and provides a simple intervention to resolve venous congestion. More attention to this complication is warranted, as mechanisms of venous occlusion in this setting are poorly understood.

\section{References}

1. Badu B, Durham III L, Joyce LD, Joyce DL. Iatrogenic superior vena cava syndrome from percutaneous right ventricular assist device. J Thorac Cardiovasc Surg Tech. 2021;6:92-4.

2. Ravichandran AK, Baran DA, Stelling K, Cowger JA, Salerno JT. Outcomes with the tandem Protek Duo dual-lumen percutaneous right ventricular assist device. ASAIO J. 2018;64:570-2.

3. Salna M, Garan AR, Kirtane AJ, Karmpaliotis D, Green P, Takayama H, et al. Novel percutaneous dual-lumen cannula-based right ventricular assist device provides effective support for refractory right ventricular failure after left ventricular assist device implantation. Interact Cardiovasc Thorac Surg. 2020;30: 499-506. 